\title{
Poverty and Breastfeeding:
} Comparing Determinants of Early Breastfeeding Cessation Incidence in Socioeconomically Marginalized and Privileged Populations in the FiNaL Study

Julia Temple Newhook, ${ }^{1, *}$ Leigh Anne Newhook, ${ }^{2}$ William K. Midodzi, ${ }^{3}$ Janet Murphy Goodridge, Lorraine Burrage, ${ }^{5}$ Nicole Gill, $^{6}$ Beth Halfyard, ${ }^{6}$ and Laurie Twells $^{7}$

\begin{abstract}
Purpose: Infant feeding differences are strongly tied to socioeconomic status. The goal of this study is to compare determinants of early breastfeeding cessation incidence in socioeconomically marginalized (SEM) and socioeconomically privileged (SEP) populations, focusing on birthing parents who intended to breastfeed.

Methods: This cohort study includes data from 451 birthing parents in the Canadian province of Newfoundland and Labrador who reported intention to breastfeed in the baseline prenatal survey. Multivariate logistic regression techniques were used to assess the determinants of breastfeeding cessation at 1 month in both SEM and SEP populations.

Results: The analysis data included 73 SEM and 378 SEP birthing parents who reported intention to breastfeed at baseline. At 1 month, 24.7\% (18/73) in the SEM group had ceased breastfeeding compared to $6.9 \%(26 / 378)$ in the SEP group. In the SEP population, score on the lowa Infant Feeding Attitude Scale (IIFAS) (odds ratio [OR] 3.33, $p=0.01$ ) was the sole significant determinant. In the SEM population, three significant determinants were identified: unpartnered marital status (OR 5.10, $p=0.05$ ), $<1 \mathrm{~h}$ of skin-toskin contact after birth (OR 11.92, $p=0.02)$, and negative first impression of breastfeeding (OR 11.07, $p=0.01$.

Conclusion: These results indicate that determinants of breastfeeding cessation differ between SEM and SEP populations intending to breastfeed. Interventions intended on improving the SEM population's postpartum breastfeeding experience using best practices, increasing support, and ensuring at least $1 \mathrm{~h}$ of skin-skin contact may increase breastfeeding rates.
\end{abstract}

Keywords: breastfeeding cessation; poverty; social determinants of health

\footnotetext{
'Janeway Pediatric Research Unit, Faculty of Medicine, Memorial University, St. John's, Canada.

Departments of ${ }^{2}$ Pediatrics and ${ }^{3}$ Clinical Epidemiology, Faculty of Medicine, Memorial University, St. John's, Canada.

${ }^{4}$ Past Provincial Breastfeeding Consultant, Past Chair of Baby-Friendly Council of Newfoundland and Labrador, St. John's, Canada.

${ }^{5}$ Perinatal Program NL, Janeway Children's Health and Rehabilitation Centre, St. John's, Canada.

${ }^{6}$ Health Analytics and Evaluation Services, Newfoundland and Labrador Centre for Health Information, St. John's, NL, Canada.

${ }^{7}$ School of Pharmacy and Faculty of Medicine, Memorial University, St. John's, Canada.
}

*Address correspondence to: Julia Temple Newhook, PhD, Janeway Pediatric Research Unit, Faculty of Medicine, Memorial University, St. John's, NL A1B 3V6, Canada, E-mail: jtemple@mun.ca

(c) Julia Temple Newhook et al. 2017; Published by Mary Ann Liebert, Inc. This is an Open Access article distributed under the terms of the Creative Commons Attribution License, which permits unrestricted use, distribution, and reproduction in any medium, provided the original work is properly cited. Mary Ann Liebert, Inc. offers reprint services for those who want to order professionally produced copies of articles published under the Creative Commons Attribution (CC BY) license. To obtain a price quote, email Reprints@liebertpub.com. Please include the article's title or DOI, quantity, and delivery destination in your email. 


\section{Introduction}

Breastfeeding is an issue of health equity. ${ }^{1}$ Socioeconomically marginalized (SEM) populations with low levels of education and income are much less likely to breastfeed than their relatively privileged peers with higher levels of income and education. ${ }^{2}$ Birthing parents ${ }^{\dagger}$ who do not breastfeed are at higher risk of negative health outcomes, including cancer, cardiovascular disease, and Type II diabetes. ${ }^{3}$ Infants who are not breastfed have higher rates of diarrhea, respiratory tract infections, otitis media, and sudden infant death syndrome. ${ }^{4,5}$ There is also evidence to suggest that children who are breastfed are less likely to suffer from chronic conditions such as Type I and Type II diabetes. ${ }^{6,7}$

The reasons for low breastfeeding rates in low-income populations are complex and strongly shaped by gender, with women bearing a disproportionate burden of poverty around the world. ${ }^{8}$ Results from our previous research showed that SEM women tend to be disadvantaged in terms of access to formal and informal breastfeeding supports, gendered childcare workloads, access to information about breastfeeding, and cultural shame around the exposure of breasts. ${ }^{9}$ Other similar research conducted in the United States has made clear that this class-based marginalization intersects with race-based marginalization with notably low levels of breastfeeding in lowincome and black populations. ${ }^{10}$ As breastfeeding is increasingly recognized as a matter of social justice, more research is needed to focus on the structural and systemic factors that hinder a birthing parent's right to breastfeed.

A feminist equity-focused analysis of breastfeeding is important given that, in Canada as in most of the global North, there is a striking contrast between what birthing parents wish to do (breastfeeding intention) and what actually happens once their child is born (breastfeeding duration rates). For example, while $90 \%$ of Canadian birthing parents initiate breastfeeding, only a quarter continue to breastfeed their infants to 6 months of age. ${ }^{11}$ To our knowledge, our study will be the first analysis of breastfeeding duration in SEM and socioeconomically privileged (SEP) populations that focuses on birthing parents who intend to breastfeed.

The main goal of this study is to examine socioeconomic status as a social determinant of health in the Canadian province of Newfoundland and Labrador (NL), through an analysis of data from the Feeding Infants in NL (FiNaL) study. Our specific research ob-

${ }^{\dagger}$ Following Farrow's (2015) example, ${ }^{27}$ we use language that is inclusive of all gender identities and families, including trans fathers, and trans-masculine and nonbinary-identified parents who may breastfeed (or chestfeed). jective is to compare determinants of early breastfeeding cessation in SEM and SEP populations in NL intending to breastfeed.

\section{Methods}

The FiNaL study is a longitudinal provincial birth cohort survey of prenatal care, birth, and infant nutrition. The methods for the FiNaL research are described in full detail in a separate publication (Twells et al., in preparation).

In brief, pregnant individuals completed questionnaires in their third trimester (phase I) with follow-up at 1-3 months (phase 2) and 6-12 months postpartum (phase 3). Questionnaires collected information on demographics and psychosocial factors, including social supports, breastfeeding knowledge, intent to breastfeed, attitudes to infant feeding, access to prenatal education, formal and informal supports, and maternity care practices, including adherence to the Baby-Friendly Hospital Initiative ${ }^{12,13}$ and the "Ten Steps for Successful Breastfeeding. ${ }^{14}$ Consenting participants were recontacted when their child was 12 months and 4 years of age (phase 4) to examine other health outcomes, including health service usage, obesity, and respiratory illnesses. Attitudes to infant feeding were measured by the Iowa Infant Feeding Attitude Scale (IIFAS), which has been validated for the NL population. ${ }^{15}$ Higher total IIFAS scores indicate more positive attitudes toward breastfeeding. Questionnaires were completed either on paper, by telephone, or through SurveyMonkey@. A full list of relevant FiNaL survey questions can be found in Supplementary Appendix SA1. A total of 1283 pregnant individuals completed the FiNaL Pre-Natal Survey.

FiNaL inclusion criteria specified English-speaking pregnant individuals at least 18 years of age, living in NL. Exclusion criteria removed infants who were premature, with major congenital disorders, or unable to feed orally $(n=59)$, birthing parents medically unable to breastfeed $(n=4)$, twins $(n=12$ [24 infants]), infants deceased at or shortly after birth $(n=2)$, and infants removed from birthing parent's custody $(n=2)$.

The SEM population in this study was defined as those participants who met either or both of two inclusion criteria:

(1) Total annual household income less than $\$ 30,000$ per year

(2) Highest level of education attained less than or equal to high school completion.

The 2012 low-income cutoff rate for a Canadian family of four in a community between 30,000 and 99,999 people is $\$ 30,945 .^{28}$ 
The SEP population was defined as those participants who met either or both of the following two criteria:

(1) Total annual household income greater than or equal to $\$ 80,000$ per year ${ }^{\S}$

(2) Highest level of education attained is a professional or postgraduate degree.

Early breastfeeding cessation is defined in this study as self-reported complete cessation of breastfeeding by 1 month postpartum.

The study sample included birthing parents who reported "Yes" to the question, Will you be breastfeeding your new baby?, conducted at the baseline prenatal survey in the third trimester.

\section{Statistical analysis}

Bivariate analyses were used to compare participants who did or did not cease breastfeeding, by variables linked to early breastfeeding cessation in existing research, including sociodemographic characteristics, hospital practices, birthing and postnatal experiences, attitudes, and measures of self-efficacy. Variables with a $p$ value $<0.1$ in $\chi^{2}$ tests were considered statistically significant and retained as covariates in the multiple logistic regression analysis.

Multivariate logistic regression techniques were used to assess the determinants of incidence of early breastfeeding cessation in both the SEM and SEP populations. Odds ratios with associated 95\% confidence intervals are reported. The independent variables included in the final model were those that were statistically significant at the $p<0.1$ level in the univariate analyses, excluding parity, which correlated with previous breastfeeding experience. All data were entered and analyzed using the Statistical Package for the Social Sciences (Version 23.0).

\section{Ethical approval}

Ethical approval for this study was received from the provincial Health Research Ethics Authority in NL, Reference No. 09.81.

\section{Results}

In total, we analyzed provincial data for 451 individuals. From the initial 1283 pregnant individuals who completed the FiNaL Prenatal Survey, 51.3\% $(n=658)$ completed the Post-Natal 1 (PN1) Survey, including sections

${ }^{\S}$ This was the highest income category measured in the FiNaL survey. determining 1-month feeding mode, and met the study inclusion criteria. Of this total, $14.3 \%(n=94)$ of respondents were categorized as SEM. A total of 59.7\% $(n=393)$ of PN1 respondents were categorized as relatively SEP. Finally, within these groups, $77.7 \%(n=73)$ of the SEM and $96.2 \%(n=378)$ of the SEP population reported intention to breastfeed in the prenatal questionnaire, for a total of $n=451$ individuals.

The analysis in this study compares the infant feeding patterns and determinants of early weaning of the SEM and SEP groups. Table 1 presents the descriptive analysis, comparing the demographic characteristics of participants, measures of the hospital experience, measures of self-efficacy, and a measure of attitudes toward infant feeding. At 1 month, 24.7\% (18/73) in the SEM group had ceased breastfeeding compared to 6.9\% (26/ 378) in the SEP group.

Table 2 presents the overall univariate analysis of determinants of incidence of early breastfeeding cessation for the combined population $(n=451)$ of SEM and SEP populations. The incidence of early breastfeeding

Table 1. Comparison of Characteristics of Socioeconomically Marginalized $(n=73)$ and Socioeconomically Privileged $(n=378)$ Participants Who Intended to Breastfeed

\begin{tabular}{|c|c|c|}
\hline Variable & $\begin{array}{c}\text { SEM } \\
\text { population } \\
(n=73)\end{array}$ & $\begin{array}{c}\text { SEP } \\
\text { population } \\
(n=378)\end{array}$ \\
\hline Prenatal & $\%$ of $n$ & $\%$ of $n$ \\
\hline Mother/birthing parent age $18-25$ years & 47.9 & 2.9 \\
\hline Marital status: unpartnered & 34.2 & 0.8 \\
\hline $\begin{array}{l}\text { Lower than average prenatal IIFAS } \\
\text { score }(\leq 68.1)\end{array}$ & 53.4 & 38.4 \\
\hline No previous breastfeeding experience & 71.2 & 58.2 \\
\hline Never breastfed as an infant & 58.9 & 55.6 \\
\hline Residence in a rural community-small town ${ }^{a}$ & 74.0 & 45.2 \\
\hline Currently smoking & 12.3 & 1.1 \\
\hline \multicolumn{3}{|l|}{ Peri-natal } \\
\hline Cesarean section & 26.0 & 27.8 \\
\hline$<1 \mathrm{~h}$ skin-to-skin contact after birth & 68.5 & 64.0 \\
\hline Negative first impression of breastfeeding & 50.7 & 36.8 \\
\hline Inhospital supplementation & 39.7 & 24.6 \\
\hline \multicolumn{3}{|l|}{ Postnatal } \\
\hline Breastfeeding cessation by 1 month & 24.7 & 6.9 \\
\hline $\begin{array}{l}\text { Mixed formula and breastfeeding } \\
\text { in first month }\end{array}$ & 43.8 & 19.6 \\
\hline Exclusively breastfed for first month & 31.5 & 73.5 \\
\hline
\end{tabular}

${ }^{\mathrm{a}}$ Rural-small town residence was calculated using the Statistics Canada Postal Code Conversation File provided by the Newfoundland and Labrador Centre for Health Information. "Rural-small town residence" includes out-of-population center (rural) and small population center (1000 to 29,999), while "Urban residence" includes large urban population center (100,000 or greater). (There are no NL communities classified as medium population centers.)

IIFAS, lowa Infant Feeding Assessment Scale; NL, Newfoundland and Labrador; SEM, socioeconomically marginalized; SEP, socioeconomically privileged. 
Table 2. Univariate Analysis of Determinants of Early Breastfeeding Cessation in Combined Marginalized and Privileged Populations $(n=451)$

\begin{tabular}{|c|c|c|}
\hline Variable & Odds ratio & $\mathbf{p}$ \\
\hline \multicolumn{3}{|l|}{ Prenatal } \\
\hline SEM population & 4.43 & $<0.0001$ \\
\hline SEP population & Reference & \\
\hline \multicolumn{3}{|l|}{ Age of mother/birthing parent } \\
\hline $18-25$ years & 2.16 & 0.07 \\
\hline$>25$ years & Reference & \\
\hline \multicolumn{3}{|l|}{ Marital status } \\
\hline Unpartnered & 6.36 & $<0.0001$ \\
\hline Partnered & Reference & \\
\hline Low prenatal IIFAS score $(\leq 68.1)$ & 3.52 & $<0.0001$ \\
\hline High prenatal IIFAS score $(>68.1)$ & Reference & \\
\hline \multicolumn{3}{|l|}{ Previous breastfeeding experience } \\
\hline Yes & Reference & 0.64 \\
\hline No & 1.17 & \\
\hline \multicolumn{3}{|l|}{ Was breastfed as an infant } \\
\hline Yes & Reference & 0.05 \\
\hline No & 1.99 & \\
\hline Rural-small town & 1.11 & 0.74 \\
\hline Urban & Reference & \\
\hline \multicolumn{3}{|l|}{ Currently smoking } \\
\hline Yes & 6.39 & 0.002 \\
\hline No & Reference & \\
\hline \multicolumn{3}{|l|}{ Peri-natal } \\
\hline Cesarean delivery & 1.58 & 0.17 \\
\hline Vaginal delivery & Reference & \\
\hline$\geq 1 \mathrm{~h}$ skin-to-skin contact after birth & Reference & 0.07 \\
\hline$<1 \mathrm{~h}$ skin-to-skin contact after birth & 1.96 & \\
\hline Negative first impression of breastfeeding & 4.31 & $<0.0001$ \\
\hline $\begin{array}{l}\text { Neutral/positive first impression } \\
\text { of breastfeeding }\end{array}$ & Reference & \\
\hline \multicolumn{3}{|l|}{ Inhospital supplementation } \\
\hline Yes & 2.77 & 0.002 \\
\hline No & Reference & \\
\hline
\end{tabular}

cessation was significantly associated with factors such as age of birthing parent, marital status, IIFAS score, smoking status, whether the participant had been breastfed as an infant, skin-to-skin contact after birth, first impression of breastfeeding, and inhospital supplementation $(p<0.1)$ (Table 2).

As shown in Table 3, when the analysis was conducted separately in the two groups, including the multivariate analysis of the significant factors in Table 2, one independent variable made a unique statistically significant contribution in the SEP model: low IIFAS score. Negative first impression of breastfeeding does near significance at the $p<0.05$ level. The marital status and currently smoking variables were removed from the SEP model, given that the number of unpartnered participants and current smokers numbered $n<5$ in the SEP population. This model was statistically significant, $\chi^{2}(6$, $N=378)=16.30, p<0.000$. In contrast, in the SEM population, three independent variables made a unique statistically significant contribution: marital status, $1 \mathrm{~h}$ of skin-to-skin contact, and negative first impression of breastfeeding. The model containing these three determinants was statistically significant, $\chi^{2}(8, N=73)=30.49$, $p<0.0001$. The model with these three determinants explained between $34.1 \%$ and $50.7 \%$ of the variance and correctly classified $86.3 \%$ of cases (Table 3 ).

In addition, analysis of interaction terms in the combined model revealed that SEM population $\times 1 \mathrm{~h}$ skinto-skin contact was the sole interaction term to reach statistical significance at the $p<0.05$ level.

\section{Discussion}

In a Canadian provincial population of birthing parents intending to breastfeed $(n=451)$, breastfeeding cessation rates at 1 month postpartum were more than three and a half times higher in the SEM population $(24.7 \%)$ compared to the SEP population (6.9\%). In this study, to focus specifically on the role of socioeconomic status as a social determinant of health, we created a hybrid dataset that combined populations at each end of the socioeconomic spectrum. Our focus specifically on individuals who intended to breastfeed allowed us to explore factors that determined early breastfeeding cessation as obstacles to the birthing parent's right to breastfeed.

\section{SEP population}

In the SEP population, attitudes (as measured by the IIFAS) were the sole significant determinant, with birthing parents scoring below average on the IIFAS over thrice as likely to cease breastfeeding by 1 month postpartum. This finding echoes our earlier study on determinants of nonmedical supplementation in hospital, ${ }^{17}$ as well as research on determinants of breastfeeding duration in the general population, which has demonstrated that attitude toward breastfeeding is a powerful predictor of breastfeeding initiation and duration. ${ }^{16-19}$

\section{SEM population}

Previous research on breastfeeding in SEM populations has identified numerous determinants of cessation, including age, ${ }^{10,20,21}$ education, ${ }^{20,22}$ income,${ }^{20}$ marital status or presence of a partner, ${ }^{20,23,24}$ ethnic minority status, ${ }^{20}$ parity, ${ }^{22}$ previous breastfeeding experience, ${ }^{21}$ return to work, ${ }^{24}$ smoking status, ${ }^{22,24}$ breastfeeding support from family and friends, ${ }^{22}$ and encouragement and advice from a physician for breastfeeding. ${ }^{24}$ However, we have found no other studies that focused 
Table 3. Comparative Multivariate Analysis of Determinants of Early Breastfeeding Cessation in Socioeconomically Marginalized $(n=73)$ and Socioeconomically Privileged Populations $(n=378)$ Intending to Breastfeed

\begin{tabular}{|c|c|c|c|c|}
\hline \multirow[b]{2}{*}{ Variable } & \multicolumn{2}{|c|}{ SEM population $(n=73)$} & \multicolumn{2}{|c|}{ SEP population $(n=378)$} \\
\hline & Odds ratio & p & Odds ratio & $\mathrm{p}$ \\
\hline \multicolumn{5}{|l|}{ Prenatal } \\
\hline \multicolumn{5}{|l|}{ Age of mother/birthing parent } \\
\hline 18-25 years & $\begin{array}{c}0.73 \\
\text { Reference }\end{array}$ & 0.69 & 1.00 & 1.00 \\
\hline \multicolumn{5}{|l|}{ Marital status } \\
\hline $\begin{array}{l}\text { Unpartnered } \\
\text { Partnered }\end{array}$ & 5.10 & 0.048 & N/A & \\
\hline $\begin{array}{l}\text { Partnered } \\
\text { Low prenatal IIFAS score }(\leq 68.1)\end{array}$ & Reference & 065 & 333 & 1 \\
\hline $\begin{array}{l}\text { Low prenatal IIFAS score }(\leq 68.1) \\
\text { Hiah prenatal IIFAS score }(>68.1)\end{array}$ & 1.41 & 0.05 & כ3. & 0.01 \\
\hline $\begin{array}{l}\text { High prenatal IIFAS score }(>68.1) \\
\text { Was breastfed }\end{array}$ & Reference & & & \\
\hline \multicolumn{5}{|l|}{ Was breastfed as an infant } \\
\hline Yes & Reference & 0.55 & 1.23 & 0.64 \\
\hline No & 1.69 & & & \\
\hline \multicolumn{5}{|l|}{ Currently smoking } \\
\hline Yes & 5.67 & 0.11 & N/A & \\
\hline No & Reference & & & \\
\hline \multicolumn{5}{|l|}{ Peri-natal } \\
\hline$\geq 1 \mathrm{~h}$ skin-to-skin contact after birth & 11.92 & 0.02 & 1.19 & 0.70 \\
\hline$<1 \mathrm{~h}$ skin-to-skin contact after birth & Reference & & & \\
\hline Negative first impression of breastfeeding & 11.07 & 0.01 & 2.37 & 0.053 \\
\hline Neutral/positive first impression of breastfeeding & Reference & & & \\
\hline \multicolumn{5}{|l|}{ Inhospital supplementation } \\
\hline Yes & 1.75 & 0.48 & 1.19 & 0.71 \\
\hline No & Reference & & & \\
\hline
\end{tabular}

specifically on breastfeeding outcomes among SEM birthing parents who intended to breastfeed.

One of the most important points to identify in this study is that, in contrast to the SEP population, attitudes were not a significant determinant of breastfeeding cessation in the SEM population. Instead, our analysis of breastfeeding cessation in the SEM population pointed strongly to the gendered, social structural elements that shaped these women's and birthing parents' lives.

The first determinant pointed to the importance of partner support: single birthing parents were more than five times as likely as partnered birthing parents to cease all breastfeeding by 1 month. This echoes existing research that has identified marital/partner status as an important determinant of breastfeeding duration in SEM populations. ${ }^{20,21,24}$

The two remaining determinants of breastfeeding cessation in this population, (1) negative first impression of breastfeeding in hospital and (2) lack of skinto-skin contact after birth, point to key elements of the postpartum experience. Birthing parents who had a negative first impression of breastfeeding in hospital were $>11$ times as likely to cease breastfeeding by 1 month. More than half of SEM participants reported a negative first impression of breastfeeding in hospital. This finding supports previous research that has found that the experience of an initial breastfeeding problem in hospital is a determinant of early breastfeeding cessation ${ }^{10}$ and that early positive experiences are an important enabler of continuation of breastfeeding. ${ }^{25}$ Qualitative research has found that positive experiences in the early days of breastfeeding are crucial to breastfeeding duration for lowincome birthing parents and that "[a]ccess to advice at the right time is a key issue for some low-income women." 25 , p. 240

Birthing parents who had no contact or $<1 \mathrm{~h}$ of skin-to-skin contact with their infant after birth were nearly 12 times as likely to cease breastfeeding by 1 month. Less than one-third of SEM birthing parents reported an hour of skin-to-skin contact with their infant after birth. This finding may have importance beyond breastfeeding cessation, given that research suggests that immediate postpartum skinto-skin and suckling are connected to positive parent-child interaction at 1 year compared to dyads where birthing parent and child were separated after birth. ${ }^{26}$

This study supports four recommendations to better support SEM birthing parents who wish to exclusively breastfeed. 
(1) Increased birthing and postpartum supports for unpartnered birthing parents;

(2) Respectful and empowering birthing and postpartum care that focuses on building SEM birthing parents' trust and confidence in their bodies, abilities, and knowledge of normal feeding behaviors and needs of their newborns;

(3) Public education explaining the importance of skin-to-skin practices for newborns and birthing parents; and

(4) Qualitative intervention research to explore provider and parental experiences regarding early breastfeeding and skin-to-skin practices in SEM populations.

\section{Conclusion}

The findings of our study are particularly striking, given the public health emphasis on individual responsibility for breastfeeding "success" and on promoting positive breastfeeding attitudes. Our research suggests that the focus on attitudes may be less relevant to a SEM population intending to breastfeed. Our findings also reveal that most SEM mothers and birthing parents in our province want to breastfeed and that two of the main determinants of whether or not they are able to do so require not individual change, but structural systemic changes in postpartum care.

\section{Strengths and limitations}

This study is a province-wide prospective cohort of individuals in a Canadian province. There was a short recall period for each questionnaire, giving the study an advantage over retrospective studies which ask participants to recall and report previous infant feeding details.

However, our study is susceptible to the limitations inherent in voluntary, self-reported questionnairebased surveys. We used province-wide, populationbased recruitment strategies, but an infant feeding questionnaire is likely to interest a population with more positive attitudes toward breastfeeding and a higher socioeconomic status compared to the general population. In addition, there was no clinical chart review to confirm or validate the information reported on the questionnaires.

\section{Author Disclosure Statement}

No competing financial interests exist.

\section{References}

1. Pérez-Escamilla R, Sellen D. Equity in breastfeeding: where do we go from here? J Hum Lact. 2015;31:12-14.

2. Millar WJ, Maclean H. Breastfeeding practices. Health Rep. 2005;16:23-31.

3. Bartick MC, Stuebe AM, Schwarz EB, et al. Cost analysis of maternal disease associated with suboptimal breastfeeding. Obstet Gynecol. 2013;122:111-119.

4. Hanson, LA. Human milk and host defence: immediate and long-term effects. Acta Pediatr Supp. 1999;430:46.

5. Plagemann A, Harder T. Breastfeeding and the risk of obesity and related metabolic diseases in the child. Metab Syndr Relat Disord. 2005;3:222232.

6. Rosenbauer J, Herzig P, Giani G. Early infant feeding and risk of type 1 diabetes mellitus-a nationwide population-based case-control study in pre-school children. Diabetes Metab Res Rev. 2008;24:211-222.

7. Gerstein HC. Cow's milk exposure and type 1 diabetes. Diabetes Care. 1994;17:13-19.

8. Duffy A, Mandell N. Poverty in Canada. In: Gender and Women's Studies in Canada. Edited by Hobbs M, Rice C. Toronto: Women's Press, 2013, pp. 606-616.

9. Temple Newhook J, Ludlow V, Newhook LA, et al. Understanding the social context that shapes low-income women's perceptions and experiences of infant feeding. Can J Nurs Res. 2013;45:28-49.

10. Merewood A, Patel B, Newton KN, et al. Breastfeeding duration rates and factors affecting continued breastfeeding among infants born at an inner-city US Baby-Friendly hospital. J Hum Lact. 2007;23:157-164.

11. Public Health Agency of Canada. Breastfeeding and infant nutrition. 2014. Available at www.phac-aspc.gc.ca/hp-ps/dca-dea/stages-etapes/ childhood-enfance_0-2/nutrition/index-eng.php Accessed December 15, 2016.

12. Breastfeeding Committeee of Canada. Baby-Friendly initiative integrated indicators. 2011. Available at www.breastfeedingcanada.ca/documents/ BCC_BFI_20110704_Final_BCC_BFI_Integrated_Indicators_English.pdf Accessed December 15, 2016.

13. World Health Organization. Evidence for the ten steps to successful breastfeeding. 1998. Available at www.who.int/maternal_child adolescent/documents/9241591544/en Accessed December 15, 2016.

14. Breastfeeding Committee of Canada. Integrated 10 steps and WHO code practice outcome indicators for hospitals and community health services: summary. 2012. Available at http://breastfeedingcanada.ca/documents/ 2012-05-14_BCC_BFI_Ten_Steps_Integrated_Indicators_Summary.pdf Accessed December 15, 2016.

15. Twells L, Midodzi WK, Ludlow V, et al. Assessing infant feeding attitudes of expectant women in a provincial population in Canada: validation of the lowa Infant Feeding Attitude Scale. J Hum Lact. 2014;30:1-10.

16. Chambers J, Mclnnes $R$, Hoddinott $P$, et al. A systematic review of measures assessing mothers' knowledge, attitudes, confidence and satisfaction towards breastfeeding. Breastfeed Rev. 2007;15:17-25.

17. Temple Newhook J, Newhook LA, Midodzi WM, et al. Determinants of nonmedically indicated in-hospital supplementation of infants whose birthing parents intended to exclusively breastfeed. J Hum Lact. 2017;33:278-284.

18. de la Mora A, Russell D, Dungy $C$, et al. The lowa Infant Feeding Attitude Scale: analysis of reliability and validity. J Appl Soc Psychol. 1999;29:2362-2380.

19. Wilkins C, Ryan K, Green J, et al. Infant feeding attitudes of women in the United Kingdom during pregnancy and after birth. J Hum Lact. 2012;28:547-555.

20. Mathews M, Leerkes EM, Lovelady CA, et al. Psychosocial predictors of primiparous breastfeeding initiation and duration. J Hum Lact. 2014;30:480-487.

21. Tenfelde, SM, Finnegan L, Michaels Miller A, et al. Risk of breastfeeding cessation among low-income women, infants and children. Nurs Res. 2012;61:86-95.

22. Simard, I. Factors influencing the initiation and duration of breastfeeding among low-income women followed by the Canada prenatal nutrition program in 4 regions of Quebec. J Hum Lact. 2005;21: 327-37. 
23. Darfour-Oduro SA, Kim J. WIC mothers' social environment and postpartum health on breastfeeding initiation and duration. Breastfeed Med. 2014;9:524-29.

24. Racine EF, Frick KD, Strobino D, et al. How motivation influences breastfeeding duration among low-income women. J Hum Lact. 2009;25: 173-81.

25. Bailey C, Pain RH, Aarvold JE. A 'give it a go' breast-feeding culture and early cessation among low-income mothers. Midwifery. 2004; 20:240-250.

26. Bystrova K, Ivanova V, Edhborg M, et al. Early contact versus separation: effects on mother-infant interaction one year later. Birth. 2009;36:97-109.

27. Farrow A. Lactation support and the LBGTQI community. J Hum Lact. 2015;31:126-128.

28. Statistics Canada. Income Research Paper Series-Research Paper 75F0002M. 2013. Available at www.statcan.gc.ca/pub/75f0002m/ 2013002/lico-sfr-eng.htm Accessed May 25, 2017.
Cite this article as: Temple Newhook J, Newhook LA, Midodzi WK, Murphy Goodridge J, Burrage L, Gill N, Halfyard B, Twells L (2017) Poverty and breastfeeding: comparing determinants of early breastfeeding cessation incidence in socio-economically marginalized and privileged populations in the FiNaL study, Health Equity 1:1, 96-102, DOI: 10.1089/heq.2016.0028.

\section{Abbreviations Used}

FiNaL $=$ Feeding infants in Newfoundland and Labrador IIFAS = lowa Infant Feeding Attitude Scale

$\mathrm{NL}=$ Newfoundland and Labrador

$\mathrm{OR}=$ odds ratio

SEM = socioeconomically marginalized

$\mathrm{SEP}=$ socioeconomically privileged

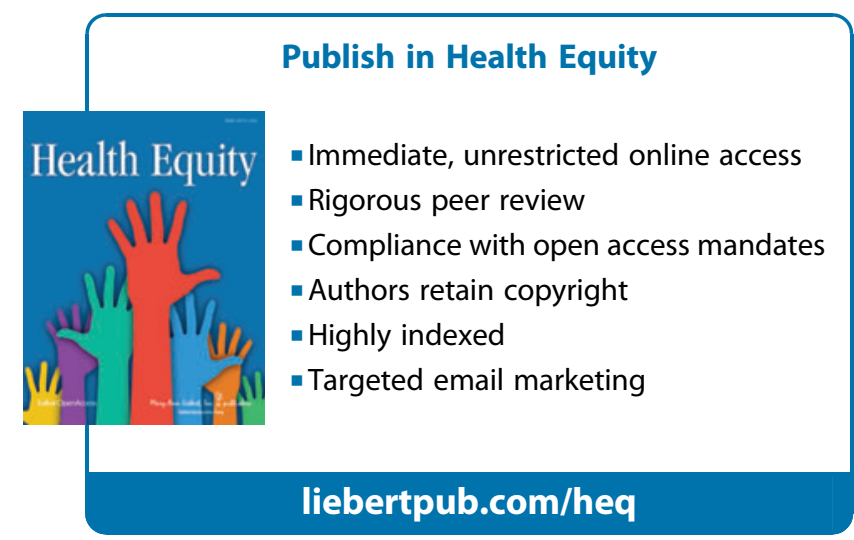

